\title{
Activity Based Smart Lighting Control For Energy Efficient Building By Neural Network Model
}

\author{
Ivan Hidayat ${ }^{1}$, Faridah ${ }^{2 *}$, and Sentagi Sesotya Utami $^{2}$ \\ ${ }^{1}$ Student of Engineering Physics Department, Gadjah Mada University, Indonesia. \\ ${ }^{2}$ Lecturer of Engineering Physics Departement, Gadjah Mada Unviersity, Indonesia.
}

\begin{abstract}
The goal of this research is to attain a smart control algorithm that can be used in a lighting system based on the activities of a building's occupants, using the neutral network model method. The study case of this research is the activities inside the Asrama Mahasiswa Kinanti UGM building. Control algorithm was built based on qualitative data from the occupants of the building, which were more or less the daily activities of the occupants. The results of the qualitative data will be essential in choosing a sensor and its placement. Several scenarios of activities represented by the combination of sensors' outputs are used as the control system input. The optimum illumination of the lighting system for these scenarios was produced through simulation using DIALux. An artificial neural network model was then developed and used as the smart control algorithm. Input for the neural network is the combination of sensor output and illumination output for each scenarios, given the simulation results. Based on the qualitative data acquired through a survey of the occupants' activities, the design of the lighting control system requires a system that uses occupancy sensors, weight sensors, photoelectric sensors, and photo sensors. The various positions and activities being done by the occupants are represented by the sensors output. A manual remote will be used to adjust the sensors regarding details that cannot be specifically detected. Ongoing specific activities inside the inhabited room gives off a system output. This scenario portrays the lighting conditions of the room, which includes the number of lights that are turned on or turned off. A smart control algorithm was developed using the backpropagation neural network model with 10 neuron inputs, the first hidden layer with 20 neurons, second hidden layer with 20 neurons, whilst the output layer has 5 neurons. The activated function for the first hidden layer is tan-sigmoid, for the second hidden layer is log-sigmoid, and the output layer is using pure linear. The training function uses trainlm. The MSE system's value is $2.72 \times 10-8$ with a larger $\mathrm{R}$ total value, which is 0.99892 .
\end{abstract}

\section{Problem Statement}

Visual comfort is one of the important factors of a building that needs to be considered. Visual comfort relates on how well a person can work under the lighting condition provided. In order to achieve the desirable visual comfort, most buildings are designed with artificial lighting systems, which consume electricity or energy. The electricity energy for lighting system is approximately $20-40 \%$ of the total energy consumption of a building [1].

Several attempts have been done to reduce the lighting system energy consumption, which mostly by replacing the light bulbs with highly efficient bulbs such as LED. By still creating the same visual comfort, the lighting system energy consumption can be reduced up to $55 \%$ [2].

Building automation technology is another alternative way to reduce the energy consumption. Many innovations of lighting automation system have been done. Target of the design is a system that consumes less energy but still maintains occupant's visual comfort. A system that enables to perform such task by utilizing daylight as the light source. Not only it is energy efficient, it also creates light quality that is suitable to human's visual response $[3,4]$. Daylight sensor is use to depict the availability of daylighting in a room. Some researches have added occupancy sensor to identify a human presence in a room $[5,6]$. Based on the sensors' outputs, scenarios of control are created such as on off switch control or dimming, where the goal is to avoid excessive energy consumption of the lighting system.

Human activities are also a factor that can be used as the consideration in developing a lighting control system. Location of occupants and their activities in a building can also be used to define the amount of lighting intensity required for each part of the lighting system. Building automation technology using smart control algorithm enables a lighting system to perform well while considering the human's location and activity factor. A method that is commonly used to develop a smart control algorithm is Artificial Neural Network $[6,7]$.

Kinanthi dormitory is a student's dormitory owned by Universitas Gadjah Mada (UGM) with total occupants of 368 persons. Each room has a capacity of two persons. It is one of the green building icon for UGM. As a green building, the building energy consumption should be efficient. Therefore, lighting automation system in this dormitory is needed to create a

Corresponding author: faridah@ugm.ac.id 
living space that is energy efficient and still supports the students' academic needs.

In this paper, the research aim to create a smart control algorithm for lighting system based on occupant's activity pattern using artificial neural network. Kinanthi dormitory in UGM is used as the case study. Quantitative data were obtained from observation on the occupant's daily activity pattern and used as a consideration in selecting the sensor and its placement. Several control scenarios representing output of the sensors are being ordered and used as the control system inputs. The optimal lighting intensity of the lighting system produced by these scenarios was observed through computer simulation using Dialux. The SNI 036197-2000 was used as preferences. The artificial neural network was then developed as the control system algorithm by inserting several combinations of the sensors' outputs and the lighting intensity outputs obtained from each scenarios.

\section{Methodology}

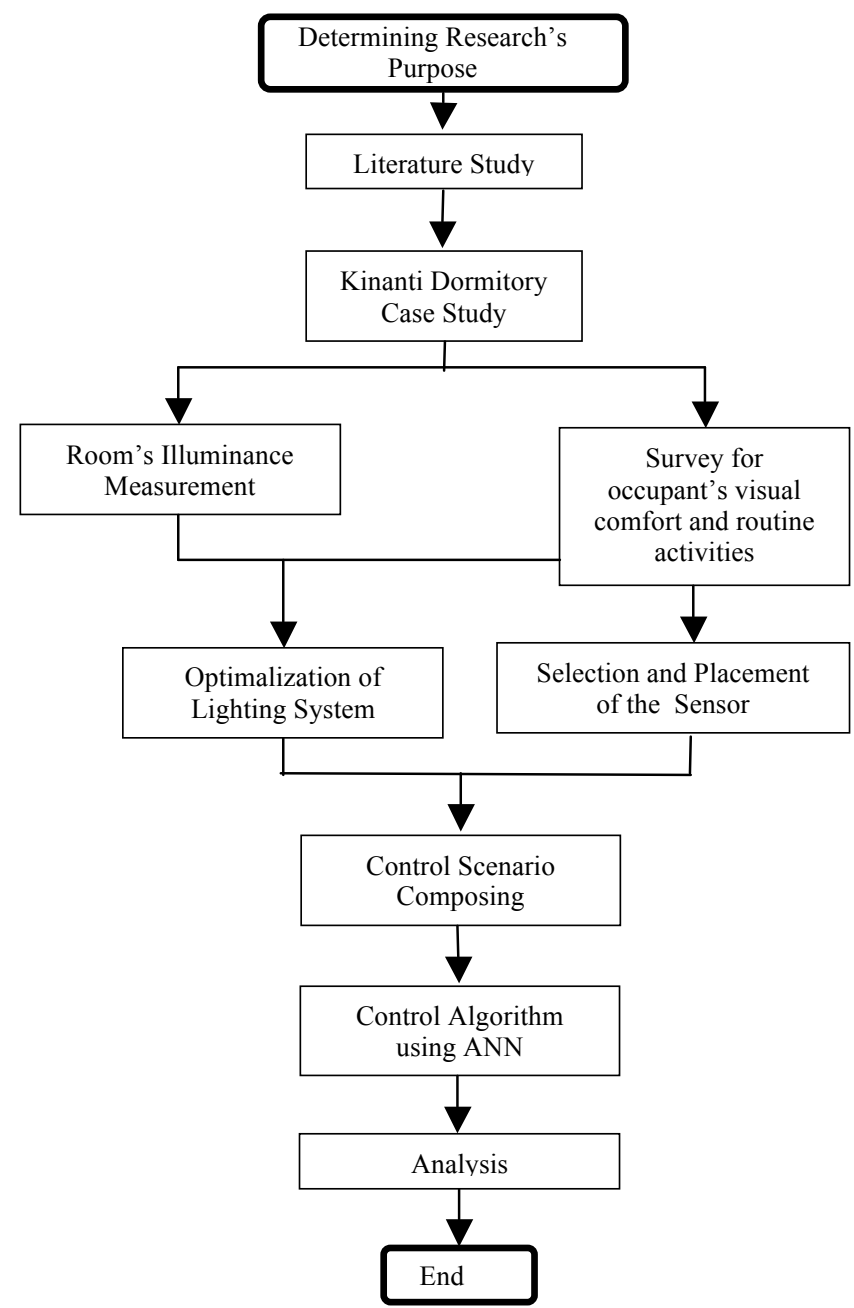

Fig 1. Research Methodology.

The research diagram is shown in Figure 1. The profile of Kinanthi dormitory in UGM used as the case studied was obtained from the interior design drawings as shown in Figure 2.a. However, after the building was built, the interior is slightly different than the design as shown in Figure 2.b.

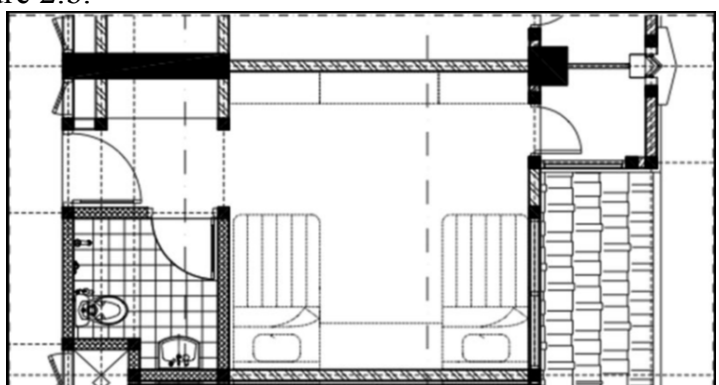

(a)

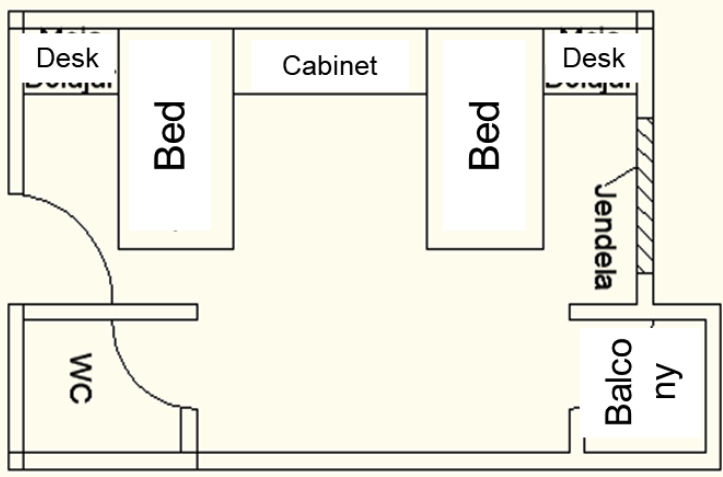

(b)

Fig.2. Living area of Kinanthi Dormitory UGM: (a) As built drawing (b) existing.

Table 1. Questionaire's questions about exting visual comfort.

\begin{tabular}{|c|c|c|}
\hline No. & Desired Information & Question \\
\hline 1 & $\begin{array}{l}\text { Occupants' visual } \\
\text { comfort. This } \\
\text { information is used to } \\
\text { know whether lighting } \\
\text { system need to be } \\
\text { improved or not. }\end{array}$ & $\begin{array}{l}\text { Do you still meet } \\
\text { problems to do } \\
\text { activities with lighting } \\
\text { in the room? (for } \\
\text { example: too dark or } \\
\text { blinded by the glare) }\end{array}$ \\
\hline 2 & Daylighting's comfort & $\begin{array}{l}\text { Is the sunlight too } \\
\text { bright to be used as } \\
\text { light source in the } \\
\text { afternoon? }\end{array}$ \\
\hline 3 & $\begin{array}{l}\text { Certain area in the } \\
\text { bedroom that is } \\
\text { comfortable to study. }\end{array}$ & $\begin{array}{l}\text { Which area in the } \\
\text { bedroom that you feel } \\
\text { comfortable for } \\
\text { studying? }\end{array}$ \\
\hline 4 & Study's Time & $\begin{array}{l}\text { What time do you } \\
\text { study everyday? }\end{array}$ \\
\hline 5 & $\begin{array}{l}\text { Comfortable lighting } \\
\text { to sleep. }\end{array}$ & $\begin{array}{l}\text { How is the lighting that } \\
\text { you wanted to sleep? }\end{array}$ \\
\hline 6 & $\begin{array}{l}\text { Time spent by the } \\
\text { occupant to stay inside } \\
\text { the room for each day. }\end{array}$ & $\begin{array}{l}\text { How long do you stay } \\
\text { inside the room for } \\
\text { each day? }\end{array}$ \\
\hline
\end{tabular}

Each space rent in the dormitory provides space for desks for studying, beds, and an indoor bathroom. This research focuses on the functioning of the space(s) for studying and rest activities only. The Survey was conducted to understand the existing visual comfort and provided qualitative data of the activities that are commonly done by the occupants. The survey utilized 
questionnaire as the instrument with random respondents from the occupants. The questionnaire consists of questions that address expected data as shown in Table 1. Respondents responded to the questionnaire by choosing an answer for each question. This closed questionnaire technique was used to simplify the analysis.

Question no. 1-2 in Table 1 are questions related to the visual comfort level of the existing lighting system. Responses to this questions combined with the illumination measurement result of the room are used to see whether the existing lighting system requires some optimization or not. Meanwhile, question number $3-5$ in Table 1 are questions that addressed the relationship between the occupant's routine activity and other room functions that are actually provided. Responses to these questions are used to select the sensor's type and its placement.

Control scenario is the scenario that might possibly apply for the Kinanthi dormitory lighting system, given the relationship between input and output of the controller. Inputs of the controller output' combinations from the sensors installed. These output' combinations describe types and position of activities and the amount of daylight's availability. Meanwhile, outputs of the controller are actuators' signal that will switch on and off the lighting fixtures of the room, with a combination relevant to the inputs. The illumination distribution from all the combinations action of the actuators was simulated in order to ensure the lighting intensity is suitable for each activity according to SNI 03-61972000.

The relations between outputs and inputs that generated the control scenarios are then used to create the Artificial Neural Network model. Briefly, artificial neural network (ANN) is one of algorithm machine that simulates the work of living creature nerves system. The ANN can be used to model a complex relation between input and output of a system in order to find the data pattern.

\section{Results}

\subsection{Illumination existing condition}

Figure 3 provides the lighting intensity measurement of the dormitory room. From the measurement results, it shows that during the daytime, the daylighting covers most of the space with an intensity level that complies the SNI standard for studying. However, during night time, the artificial lighting is not providing a sufficient intensity level for studying on the workspace area.

Meanwhile, from the survey result of the visual comfort level, there are several findings as follow. First, $50 \%$ of the respondents feel neutral of the lighting quality. This indicates that occupants do not have complains about the darkness or brightness of the room. Thirty percent of the respondents agree that there is a lighting problem in the room and $20 \%$ disagree. The second result is that $40 \%$ of the respondents are not seeing daylighting as a source light that creates glare. Forty percent feels normal to have daylighting during daytime and $20 \%$ agree that sunlight is to glare for a daytime light source.
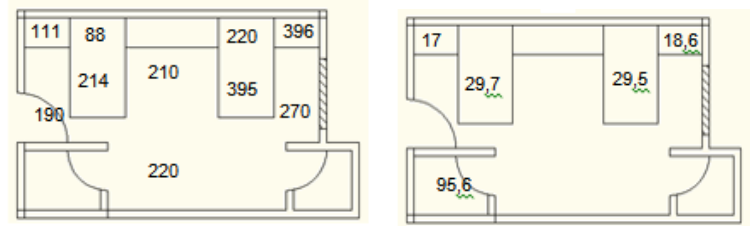

Fig.3. In-site measurement result in the living area (lux) (left) daytime with daylighting, and (right) at night using artificial lighting.

The lighting system optimization is required based on the result of the measurement and visual comfort survey. Furthermore, artificial lighting condition should be improved meanwhile the daylighting is already acceptable. Improvement of the artificial lighting is necessary since the illumination level of the existing condition does not meet the standard even though there were no complaints from the occupants.

\subsection{Artificial Lighting Optimization}

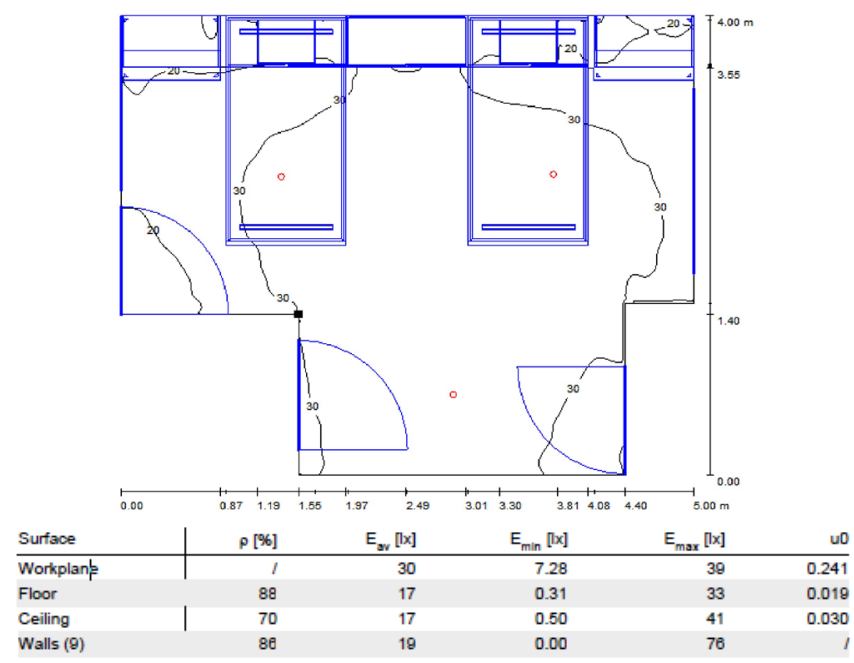

Fig. 4. Simulation of the existing condition.

Results of the simulated lighting condition of the existing room are shown in Figure 4. Similar to the onsite measurement results, the simulation results were also far from the standardized visual comfort mentioned in SNI. Kinanthi dormitory still requires some changes in its artificial lighting given the average illumination of 30 lux, the highest value of 39 lux and the lowest at 7,28 lux.

An aide to the illumination quality, data obtained from in-situ measurement and computer simulation are similar by means the room modeling is close to the actual condition. This model is then used to create an optimal lighting design. Reflection factor selected from materials for the simulation is similar to the real room.

There are several optimizations done in the computer simulation. First, by replacing the LED light bulbs into LED with a higher efficacy. Three lights were replaced 
using Phillips CorePro LEDspot MV GU10 15W 1521 $\mathrm{lm}$. Figure 5.a shows the simulated illumination distribution after the light bulbs were replaced. The illumination on some area at the room corners are still not sufficient and therefore, it is still lack of lighting on the study desk. A desk lamp is needed, using Philips WL $121 \mathrm{~V} \mathrm{LED5S} / 830$ of 8 watts and $500 \mathrm{~lm}$ (see Figure 6). The simulation results of the illumination distribution can be seen in Figure 5b.

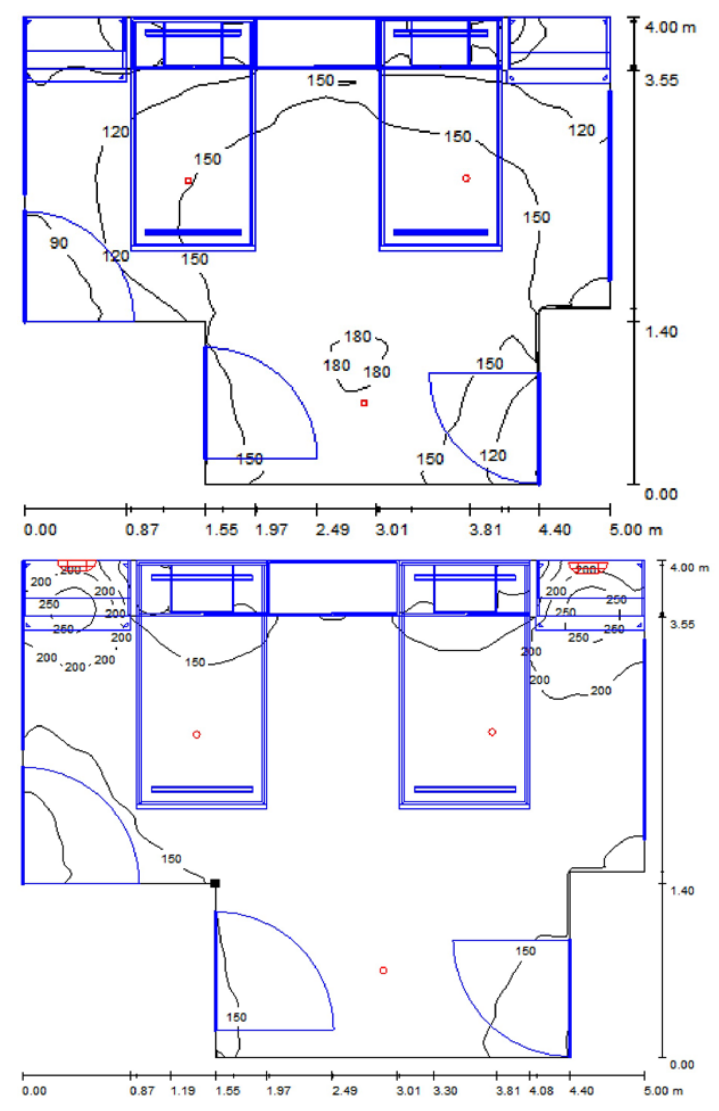

Fig.5. Simulation result of lighting intensity distribution in the living area for optimum condition: (a) without an added fixture, and (b) with an added fixture, on the study desk.

By replacing the light bulb and adding more luminaire, the lighting quality of Kinanthi dormitory room already fulfilled the required visual comfort standard provided by SNI. The average illumination on the work-plane is 172 lux with the lowest at 49 lux and the highest illumination at 288 lux. Another satisfying condition is the maximum lighting load of $3,6 \mathrm{~W} / \mathrm{m} 2$, which is lower than the (SIN specified maximum lighting load) SNI of $17 \mathrm{~W} / \mathrm{m} 2$. Table 3 provides the comparison of the existing condition with the artificial lighting optimization of the dorm.

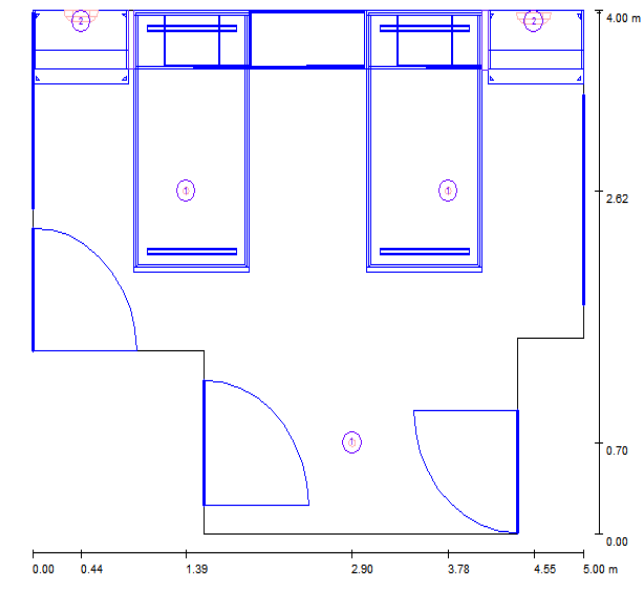

Fig.6. Fixture placement in optimum condition.

Table 3. Comparison between existing condition and optimum artificial lighting in the living area.

\begin{tabular}{|c|c|c|}
\hline Parameter & $\begin{array}{c}\text { Existing } \\
\text { Condition }\end{array}$ & $\begin{array}{c}\text { Optimum } \\
\text { condition }\end{array}$ \\
\hline $\begin{array}{c}\text { Average illumance on } \\
\text { workplane (1x) }\end{array}$ & 30 & 172 \\
\hline $\begin{array}{c}\text { Energy usage per square } \\
\text { area (W/m }{ }^{2} \text { ) }\end{array}$ & 1,06 & 3,06 \\
\hline Total Luminaire (lm) & 1050 & 5563 \\
\hline Total Power (W) & 18 & 61 \\
\hline
\end{tabular}

\subsection{Sensor and its placement}

Several survey results of the common occupant's activity in the Kinanthi Dormitory UGM are as follows,

1. Bed and study desk are areas that are commonly used for studying.

2. The usage pattern of study desk one and two are quite different, which means that each person uses their study desk at the different time.

3. There are respondents wanted their light off during sleeping, dimmed and left on by $50 \%, 30 \%$, and $20 \%$, respectively.

Based on the survey result, sensors needed for the control system were chosen, where outputs of these sensors were used to provide information on the occupant's activity and their positions in the room for each activity. Sensors used are occupancy sensors, weight sensors, photoelectric sensors and also photosensor. Placement of the sensors is described in Figure 7. Each sensor has their own function. The weight sensor is used to depict whether there is a person on the bed or not. The photoelectric sensor is used to depict whether the person is sitting or not while he was on the bed.

Three types of occupation sensors are used. First is to depict the presence of a person inside the room. Sensor two and three are used to detect whether the person is studying on the desk or not. The photosensor is used to detect the amount of intensity that entered the occupation space. Since most of the daylighting hit the window, therefore, the photosensor is able to find the correlation 
between the amount of daylight that impinged the window and the amount of intensity level that penetrates into the living area.

Besides the sensors mentioned above, remotes are also used to provide input to the sensor for several stimuli or variable that were not able to be detected specifically. For instance, occupants laying on the bed while reading a book, there is a desire between lighting level for sleeping but not totally shut down. This has created 10 types of inputs to the control system which are, 2 inputs are using weight sensors (W1 and W2), 2 photoelectric sensors (P1 and P2), 3 occupancy sensors (SO1, SO2, and SO3), 1 photosensor, and 2 inputs from the remote ( $\mathrm{R} 1$ for turning on the light when a person is reading while lying down; R2 for dimming the ambient room light and only leaving on the both desklamp).

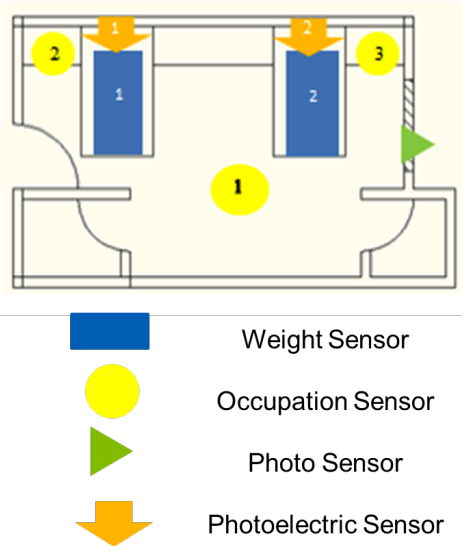

Fig.7. Sensor placement in the living area.

\subsection{Control scenarios}

Some activity's scenarios were represented by the combination of the arranged sensor output and are used as the data for the system control input. Inputs from the sensor are binary numbers. Using all 10 inputs discussed above, we will have a combination of $2^{10}$ or 1024 types of input. In this case, each input is not necessarily representing a certain occupant's activity. Activities that are given priority are the ones that require a higher illumination level. For example, in the living area, there might exist a person studying and a person sleeping, therefore, all the light fixtures will be turned on to support the studying activity. Meanwhile, if there are 2 or more simultaneous input from the remote, then none of the input is taken into consideration since the remote might be accidentally pressed.
Fig.8. Flowchart control scenario.

The controller has eight output scenarios relevant to the lighting system manipulation. Each scenario relates to a specific activity and the amount of daylighting available in the living area. Also to keep in mind that all scenarios should comply with the SNI requirements as shown in Table 4. 
Table 4. Scenario of control system outputs.

\begin{tabular}{|c|c|c|c|c|c|c|c|}
\hline \multirow{2}{*}{ Scenario } & \multicolumn{5}{|c|}{ Lighting condition } & \multirow{2}{*}{ Average illuminance (lux) } & \multirow{2}{*}{$\begin{array}{l}\text { Comply to } \\
\text { standard? }\end{array}$} \\
\hline & L1 & $\mathrm{L} 2$ & L3 & M1 & M2 & & \\
\hline Scenario 1 & 1 & 1 & 1 & 1 & 1 & 215 & Yes \\
\hline Scenario 2 & 1 & 1 & 1 & 0 & 1 & 157 & Yes \\
\hline Scenario 3 & 1 & 1 & 1 & 1 & 0 & 156 & Yes \\
\hline Scenario 4 & 1 & 1 & 1 & 0 & 0 & 140 & Yes \\
\hline Scenario 5 & 0 & 0 & 0 & 1 & 1 & 32 & Yes \\
\hline Scenario 6 & 0 & 0 & 0 & 0 & 1 & 15 & Yes \\
\hline Scenario 7 & 0 & 0 & 0 & 1 & 0 & 17 & Yes \\
\hline Scenario 8 & 0 & 0 & 0 & 0 & 0 & 0 & Yes \\
\hline
\end{tabular}

\subsection{Artificial neural network (ANN)}

The neural network model developed is the artificial neural network using Backpropagation training method. The training function used is the trainlm, which during the training, the weighting and bias values of the ANN model are refined using the Levenberg-Marquardt optimization technique. Figure 9 shows the ANN architecture. Input and output of the model are 10 neurons each, which are data output of the sensors. Five of them are on and off condition of 4 fixtures in the dorm. The model also has two hidden layers with each $n$ and $\mathrm{m}$ neurons. A number of neurons and the activation function of the hidden layers are varied to obtain a network with a high $\mathrm{R}$ correlation values. It is shown from the test result that the most optimal network architecture is the network with 20 neurons at the first hidden layer and 20 neurons at the second hidden layer. The first hidden layer activation function is tan-sigmoid, and the second is log-sigmoid while the output layer activation layer is pure linear. This architecture has $\mathrm{R}$ values for the training, validation, testing, and total of $0.98174,0.97346,0.99641$, and 0.97814 , respectively.

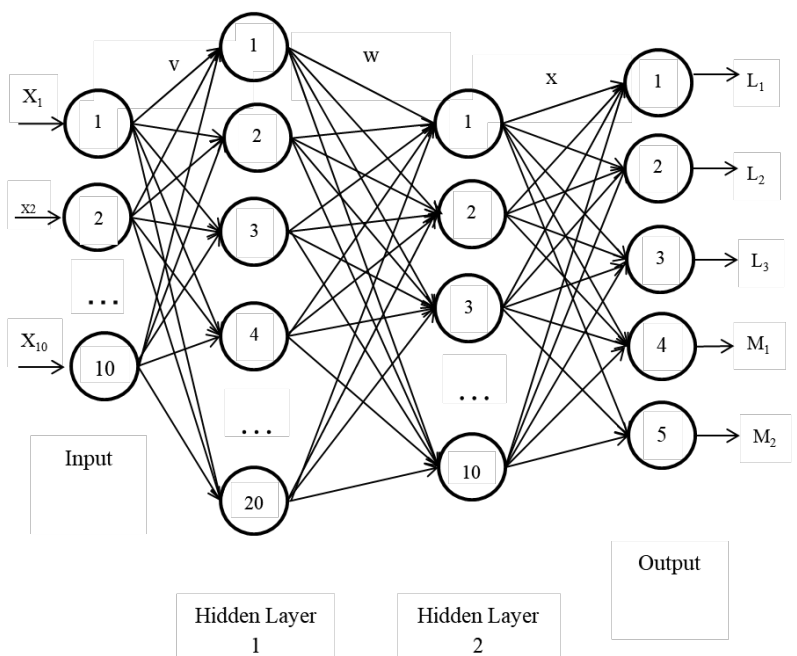

Fig.9. Architecture of the ANN Model.

The input-output pattern recognition of the network is showing that among 1024 data, there are 2 data which outputs are not suitable with the expected results during the data training process. This means that the system's performance is quite good with a system error of $0.2 \%$. Table 5 shows the unwanted data. 
Table 5. Error percentage of the designed neural network.

\begin{tabular}{|c|c|c|c|}
\hline Scenario & $\begin{array}{c}\text { Amount } \\
\text { of Data }\end{array}$ & $\begin{array}{c}\text { Amount } \\
\text { of Error }\end{array}$ & $\begin{array}{c}\text { Error } \\
\text { Percentage } \\
(\%)\end{array}$ \\
\hline Scenario 1 & 64 & 0 & 0 \\
\hline Scenario 2 & 64 & 0 & 0 \\
\hline Scenario 3 & 64 & 0 & 0 \\
\hline Scenario 4 & 46 & 0 & 0 \\
\hline Scenario 5 & 1 & 0 & 0 \\
\hline Scenario 6 & 2 & 0 & 0 \\
\hline Scenario 7 & 2 & 1 & 50 \\
\hline Scenario 8 & 781 & 1 & 1.28 \\
\hline Total & 1024 & 2 & 0.2 \\
\hline
\end{tabular}

The unrecognized input and output data are given in Table 6. After a close look, it can be seen that actually, the two unrecognized activity data are data that are hardly happening in the real world. In the first case, sensor SO1, W1, P2, and R2 are turned on, which means at the same time, there is activity in the center of the room, on bed 1 , on desk 1 , and R2 is being pressed. Meanwhile, for the second case, R1 and R2 are on at the same time, most likely the remotes were press at the same time. Therefore, the control scenario flowchart needs to be revised by adding a filter to select impossible scenarios. The refined flowchart is shown in Figure 10.

Table 6. Data with error output.

\begin{tabular}{|c|c|c|c|c|c|c|c|c|c|c|c|c|c|c|c|c|c|c|c|}
\hline \multicolumn{10}{|c|}{ Input } & \multicolumn{5}{|c|}{$\begin{array}{c}\text { Expected } \\
\text { ouput }\end{array}$} & \multicolumn{5}{|c|}{$\begin{array}{c}\text { Output from } \\
\text { iteration } \\
\text { process }\end{array}$} \\
\hline $\begin{array}{l}\mathrm{S} \\
\mathrm{O} \\
1 \\
\end{array}$ & $\begin{array}{l}\mathrm{P} \\
\mathrm{S}\end{array}$ & \begin{tabular}{|l|}
$\mathrm{S}$ \\
$\mathrm{O}$ \\
2 \\
\end{tabular} & \begin{tabular}{l|}
$\mathrm{S}$ \\
$\mathrm{O}$ \\
3
\end{tabular} & $\begin{array}{l}\mathrm{W} \\
1\end{array}$ & $\begin{array}{l}W \\
2\end{array}$ & $\begin{array}{c}\mathrm{P} \\
1\end{array}$ & $\begin{array}{l}P \\
2\end{array}$ & $\begin{array}{c}\mathrm{R} \\
1\end{array}$ & $\begin{array}{l}\mathrm{R} \\
2\end{array}$ & $\begin{array}{c}\mathrm{L} \\
1\end{array}$ & $\begin{array}{l}\mathrm{L} \\
2\end{array}$ & $\begin{array}{l}\mathrm{L} \\
3\end{array}$ & $\begin{array}{c}M \\
1\end{array}$ & $\begin{array}{c}M \\
2\end{array}$ & $\begin{array}{c}\mathrm{L} \\
1\end{array}$ & $\begin{array}{c}\mathrm{L} \\
2\end{array}$ & $I$ & $\begin{array}{c}M \\
1\end{array}$ & $\begin{array}{l}M \\
2\end{array}$ \\
\hline 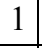 & 0 & 0 & 0 & 1 & 0 & 0 & 1 & 0 & 1 & 0 & 0 & 0 & 1 & 0 & 0 & 0 & 0 & 0 & 0 \\
\hline 1 & 0 & 0 & 0 & 1 & 1 & 0 & 0 & 1 & 1 & 0 & 0 & 0 & 0 & 0 & 1 & 1 & 1 & 0 & 0 \\
\hline
\end{tabular}

With the revised control scenario flowchart, another training of the system was done to improve the weighting values of the network. Comparison of the system's performance before and after the improvement is shown in Table 7. The R-value of the revised system is now larger, which is 0.99892 with an error of $0 \%$.

Fig.10. Control scenario flowchart with an added filter. 
Table 7. Comparison of the system's performances before and after improvement.

\begin{tabular}{|c|c|c|}
\hline & $\begin{array}{c}\text { Before } \\
\text { improvement }\end{array}$ & $\begin{array}{c}\text { After } \\
\text { improvement }\end{array}$ \\
\hline Amount of data & 1024 & 1022 \\
\hline Epoch & 58 & 30 \\
\hline $\begin{array}{c}\text { Training performance } \\
\text { (MSE) }\end{array}$ & $5,66.10^{-7}$ & $2,72.10^{-8}$ \\
\hline Gradient & $7,88.10^{-6}$ & $9,09.10^{-6}$ \\
\hline Error percentage & $0,2 \%$ & $0 \%$ \\
\hline R train & 0,99999 & 0,99973 \\
\hline R validation & 0,9944 & 0,99681 \\
\hline R tes & 0,98383 & 0,99734 \\
\hline R total & 0,9965 & 0,99892 \\
\hline
\end{tabular}

\section{Conclusion}

1. The existing artificial lighting condition has not yet met the standard SNI and therefore, optimization is required by replacing the luminance of the main light from $3501 \mathrm{~m}$ to $1521 \mathrm{~lm}$. Also by adding a luminaire at the desk to 500 lumens. By replacing and adding the fixtures, illumination in the Kinanthi dormitory room is already fulfilling the visual comfort standard with an illumination average of 172 lux on the workplane.

2. Based on results from the survey on the occupant's activity, the lighting control system is designed by,

a.Utilizing sensors of occupancy sensor, weight sensors, photoelectric sensor, and photosensor. Output of the sensors represents positions and types of activities of the occupants. For activities that are not specifically detected, a manual remote is use to provide inputs for the sensors.

b. Specific activities occurred inside the room will create system output of eight scenarios that will most likely happen. The room lighting condition and the number of fixtures switched on and off, are described by these eight scenarios.

3. The smart control algorithm is using backpropagation artificial neural network model with 10 neurons as input, first and second hidden layers each with 20 neurons, and 5 neurons in the output layer. The activation function for the first hidden layer is tansigmoid, log-sigmoid was for the second hidden layer, and pure-linear for the output layer. Training function used is trainlm. The total $\mathrm{R}$-value for the system is 0.99892 .

\section{References}

1. Commercial building energy consumption survey, EIA, Washington DC (2003)

2. Wang X., Tjalkens T., Limnartz J.P., Smart Office Lighting Control Using Occupancy Sensors, Networking, Sensing, and Control (ICNSC), IEEE $14^{\text {th }}$ International Conference (2017)

3. Liu J., Zhang W., Chu X., Liu Y., Fuzzy logic controller for energy savings in a smart LED lighting system considering lighting comfort and daylight, Energy and Buildings 127, 95-104 (2016)

4. Miranda A.C., Castaño V.M., Smart frost control in greenhouses by neural networks models, Computers and Electronics in Agriculture 137, 102-114 (2017)

5. Labeodan L., De Bukker C., Resemann A., and Zeiler W., On the Application of Wireless Sensor and Actuators Network in Existing Buildings for Occupancy Detection Occupancy-driven Lighting Control, Energy and Building 127, pp 75-83 (2016)

6. Caicedo D., Pandharipande A., Sensor-Driven Lighting Control with Illumination and Diming Constrains, IEEE Sensors Journal 15(9), pp. 51695176 (2016)

7. Wang Z., Tan Y.K., Illumination control of LED systems based on neural network model and energy optimization algorithm, Energy and Buildings 62, 514-521 (2013) 